\title{
NUMERICAL STUDY OF BIOMASS GASIFICATION IN 3D FULL-LOOP CIRCULATING FLUIDIZED BEDS USING A EULERIAN MULTI-FLUID MODEL
}

\author{
Hadi Wahyudi ${ }^{1 *}$, Mekro P Pinem ${ }^{1}$, Imron Rosyadi $^{1}$, Kevin $\mathrm{Chu}^{2}$ \\ ${ }^{1}$ Department of Mechanical Engineering, University of Sultan Ageng Tirtayasa, Jl. Jend. Sudirman \\ Km. 3 Cilegon 42435, Banten, Indonesia \\ ${ }^{2}$ Laboratory for Simulation and Modelling of Particulate Systems, Department of Chemical Engineering, \\ Monash University, Clayton, VIC 3800, Australia
}

(Received: January 2018 / Revised: January 2018 / Accepted: February 2018)

\begin{abstract}
A three-dimensional Eulerian Multi-Fluid Model (MFM) of biomass gasification in full-loop Circulating Fluidized Beds (CFBs) has been developed. The conservation equations of mass, momentum, and energy are solved by well-known Navier-Stokes formulation types. The Kinetic Theory of Granular Flow (KTGF), common chemical reactions in biomass gasification, and standard k- $\varepsilon$ turbulence model are considered. These equations are used to describe the spatial velocity, temperature, and concentration for each phase and species. The inter-solid phase heat-transfer mechanisms, which consist of direct solid-solid conduction and solid-solid conduction through fluid medium, are also considered. The results are compared to existing experimental data. It is demonstrated that the model which considers all inter-solid phase heattransfer mechanisms provides better predictions in terms of synthetic gas (syngas) compositions than the model considering direct solid-solid conduction through contact area only and the model without solid-solid heat-transfer mechanisms. From this, hydrodynamics and heat and mass transfer inside this complex system are analyzed. The results can be useful for better design and optimization of biomass gasification in CFBs.
\end{abstract}

Keywords: Full-loop circulating fluidized bed; Gasification; Multi-fluid model; Solid-solid conduction

\section{INTRODUCTION}

The increase in energy demands to support the economic growth of societies and countries, and the decrease in available natural energy resources, such as petroleum, gas, and coal, necessitate the use of renewable energy to achieve global energy security. Among the renewable resources available, biomass is the only hydrocarbon energy source that can be converted into other useful solid, liquid, and gaseous forms. Furthermore, biomass has advantages over fossil fuels, such as low carbon emissions and abundant supply. Currently, biomass comprises $14 \%$ of the total energy used worldwide.

The major problems associated with the direct use of biomass-difficulties in handling, transport, and feeding - result from its poor properties in terms of grinding and flow ability. Thus, it is necessary to convert biomass to other convenient forms such as liquid or gaseous fuels in order to improve handling and transportation. Biochemical and thermochemical processes are the two methods used to convert biomass into other forms of energy. Of these, gasification is one of thermochemical processes that is effective in producing synthetic gas

*Corresponding author's email: hadi.wahyudi@untirta.ac.id, Tel. +62-254-395502, Fax. +62-254-395440

Permalink/DOI: https://dx.doi.org/10.14716/ijtech.v9i2.1212 
(syngas). Syngas consists mainly of $\mathrm{CO}$ and $\mathrm{H}_{2}$ and can be used in fuel cells and internal combustion engines or converted into liquid fuels (Ahmad et al., 2016). Many types of biomass gasifiers, such as fixed bed, fluidized bed, and CFBs, are frequently used. Fixed bed and bubbling fluidized bed gasifier types have been intensively used in previous studies (Atnaw et al., 2012; Winaya et al., 2015) and among these CFB is one of the most promising, since it is characterized by excellent solid mixing and efficient heat and mass transfers. To date, many experimental studies have been carried out to investigate aspects of biomass gasification in CFBs, for example Guo et al. (2014), Hussain et al. (2013), Li et al. (2004), and García-Ibañez et al. (2004). Even though data and information obtained from previous experimental studies are useful in practical terms, they are less useful theoretically because they are not comprehensive enough to describe the underlying mechanism of hydrodynamics and heat and mass transfer in CFBs. Moreover, these data and information are only valid for the range of operating variables and specific CFB geometry for which they were generated. Therefore, in order to describe the behaviors of hydrodynamics, heat transfer, and chemical reaction using these data, it is necessary to replicate the operating and geometry models.

Some efforts to develop numerical models have been carried out in order to gain comprehensive information on transport phenomena in CFBs. Two common numerical approaches used are the MFM and computational fluid dynamics coupled with the discrete element method (CFDDEM). MFM is easier to use since it requires less computation than CFD-DEM. In recent years, MFM has been frequently applied to the study of biomass gasification in fluidized beds, for example Yu et al. (2007), Gerber et al. (2010), and Singh et al. (2013). Liu et al. (2013) have recently developed a numerical method in the MFM framework to study biomass gasification in the riser column of CFBs. However, their model only looked at the riser column, without consideration of the effect of solid circulation. In recent years, Liu et al. (2015), Geng et al. (2015); Guan et al. (2014) have used the MFM approach to investigate chemical looping combustion in three-dimensional full-loop CFBs. However, in these studies, heat transfer between solid phases was not considered. As pointed out by Wahyudi et al. (2016), interparticle (or solid-solid) conduction is one of the important heat-transfer mechanisms operating in fluidized beds.

In this study, biomass gasification in a three-dimensional full-loop CFB is investigated by using a MFM approach. Unlike previous studies, the conduction heat-transfer mode between solid phases (direct and through fluids) is considered in this current work. The simulation results are then compared in term of their capabilities to predict the syngas composition to models which do not include inter-solid phase heat transfer and those which include direct inter-solid phase conduction only.

\section{METHODS}

The MFM approach used in this work has been well-documented elsewhere (Singh et al., 2013; Liu et al., 2013). For convenience, a brief description of the method is presented here.

\subsection{Model Description}

In this work, the conservation equations of mass, momentum, and energy are solved by wellknown Navier-Stokes formulation types. The KTGF, common chemical reactions in biomass gasification, and the standard k- $\varepsilon$ turbulence model are considered. These equations are used to describe the spatial velocity, temperature, and concentration for each phase and species.

\subsubsection{Continuity equation}

$$
\frac{\partial \alpha_{g} \rho_{g}}{\partial t}+\nabla \cdot\left(\alpha_{g} \rho_{g} v_{g}\right)=\dot{m}_{g s}
$$




$$
\frac{\partial \alpha_{s} \rho_{s}}{\partial t}+\nabla \cdot\left(\alpha_{s} \rho_{s} v_{s}\right)=\dot{m}_{s g}
$$

where $g$ and $s$ are the subscripts for referring to the gas and solid phases, respectively. The variables of $\rho, v$, and $\alpha$ stand for density, velocity, and volume fraction, respectively. The source term of mass conservation due to chemical reactions which is evaluated between phases (gas and solid or heterogeneous reactions) is represented by $m$.

\subsubsection{Momentum equation}

$$
\begin{gathered}
\frac{\partial \alpha_{g} \rho_{g} v_{g}}{\partial t}+\nabla \cdot\left(\alpha_{g} \rho_{g} v_{g} v_{g}\right)=-\alpha_{g} \nabla \mathrm{p}+\nabla \cdot\left(\tau_{g}+\tau_{g}^{t}\right)+\alpha_{g} \rho_{g} g+\dot{m}_{g s} v_{g}+\beta\left(v_{s}-v_{g}\right) \\
\frac{\partial \alpha_{g} \rho_{g} v_{s}}{\partial t}+\nabla \cdot\left(\alpha_{s} \rho_{s} v_{s} v_{s}\right)=-\alpha_{s} \nabla \mathrm{p}+\nabla \cdot\left(\tau_{s}+\tau_{s}^{t}\right)+\alpha_{s} \rho_{s} g+\dot{m}_{s g} v_{s}+\beta\left(v_{g}-v_{s}\right)
\end{gathered}
$$

where $p, \tau, \tau^{\mathrm{t}}$, and $\beta$ are, respectively, the pressure, the viscous and Reynolds stress tensors, and the coefficient of momentum exchange between phases.

\subsubsection{Energy equation}

$$
\begin{aligned}
& \frac{\partial \alpha_{g} \rho_{g} h_{g}}{\partial t}+\nabla \cdot\left(\alpha_{g} \rho_{g} v_{g} h_{g}\right)=\nabla \cdot k_{e f f, g} \nabla T_{g}+S_{g}+Q_{s g} \\
& \frac{\partial \alpha_{g} \rho_{s} h_{g}}{\partial t}+\nabla \cdot\left(\alpha_{s} \rho_{s} v_{s} h_{s}\right)=\nabla \cdot k_{\text {eff }, s} \nabla T_{s}+S_{s}+Q_{g s}+Q_{p s}
\end{aligned}
$$

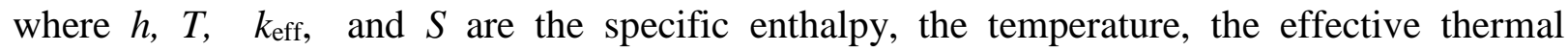
conductivity, and the source term of energy conservation due to homogeneous reactions. $Q_{\mathrm{sg}}$ and $Q_{\mathrm{gs}}$ are the heat exchange through thermal radiation between the gas and solid phases, and $Q_{\mathrm{sg}}=-Q_{\mathrm{gs}} Q_{\mathrm{ps}}$ is the heat exchange between solid phases.

2.1.4. Species transport equation

$$
\begin{gathered}
\frac{\partial \alpha_{g} \rho_{g} Y_{i, g}}{\partial t}+\nabla \cdot\left(\alpha_{g} \rho_{g} v_{g} Y_{i, g}\right)=-\nabla \cdot \alpha_{g} J_{i, g}+\alpha_{g} R_{i, g}+R \\
I_{i, g}=-\left(\rho_{g} D_{i, g}+\frac{\mu^{t}}{S c_{t}}\right) \nabla Y_{i, g}-D_{T_{i, i}} \frac{\nabla \mathrm{T}}{T}
\end{gathered}
$$

where $Y_{i} I_{i}, R_{i}, D_{i}, D_{\mathrm{T}, \mathrm{i}}, S c_{\mathrm{t}}$, and $R$ are mass fraction, diffusion flux, net production rate for homogeneous reactions, mass diffusion coefficient, thermal diffusion coefficient for component $i$, turbulent Schmidt number, and net production rate for heterogeneous reactions, respectively.

2.1.5. Interphase heat transfer equation

$$
\begin{gathered}
Q_{s g}=h_{s g}\left(T_{s}-T_{g}\right) \\
h_{s g}=\frac{6 k \alpha_{g} \alpha_{s} N u}{d_{s}^{x}} \\
N u=\left(7-10 \alpha_{s}+5 \alpha_{s}{ }^{2}\right)\left(1+0.7 R e_{s}^{0.2} \operatorname{Pr}^{1 / 3}\right)+\left(1.33-2.4 \alpha_{s}+1.2 \alpha_{s}{ }^{2}\right) \operatorname{Re}_{s}^{0.7} \operatorname{Pr}^{1 / 3}
\end{gathered}
$$

where $h_{s g}$ and $\mathrm{Nu}$ are, respectively, the solid-gas heat transfer coefficient and the Nusselt number.

\subsection{5. $P-1$ radiation model}

$$
\begin{gathered}
q_{r}=-\Gamma \nabla G \\
\Gamma=\frac{1}{3\left(a+\sigma_{g}\right)-C \sigma_{g}} \\
\nabla \cdot(\Gamma \nabla G)-a G+4 a n^{2} \sigma T^{4}=0
\end{gathered}
$$


where $q_{r}$ and $G$ are thermal radiation heat flux and incident radiation, respectively. The coefficients of absorption, scattering, and linear anisotropic phase function are referred as $a, \sigma_{s}$, and $C$, respectively, whilst $n$ and $\sigma$ stand for the refractive medium index and the StefanBoltzmann constant, respectively.

In this study, the biomass pyrolysis decomposition expressed below is considered:

Biomass $\rightarrow$ char + volatile + moisture + ash.

The heterogeneous reactions included in the model are:

$$
\begin{gathered}
\mathrm{C}+\mathrm{O}_{2} \rightarrow \mathrm{CO}_{2} \\
\mathrm{C}+\mathrm{CO}_{2} \rightarrow 2 \mathrm{CO} \\
\mathrm{C}+\mathrm{H}_{2} \mathrm{O} \rightarrow \mathrm{CO}+\mathrm{H}_{2} \\
\mathrm{C}+2 \mathrm{H}_{2} \rightarrow \mathrm{CH}_{4}
\end{gathered}
$$

Homogeneous reactions considered are as following:

$$
\begin{gathered}
\mathrm{CO}+0.5 \mathrm{O}_{2} \rightarrow \mathrm{CO}_{2} \\
\mathrm{H}_{2}+0.5 \mathrm{O}_{2} \rightarrow \mathrm{H}_{2} \mathrm{O} \\
\mathrm{CH}_{4}+2 \mathrm{O}_{2} \rightarrow \mathrm{CO}_{2}+2 \mathrm{H}_{2} \mathrm{O} \\
\mathrm{C}_{2} \mathrm{H}_{4}+\mathrm{O}_{2} \rightarrow 2 \mathrm{CO}+2 \mathrm{H}_{2} \\
\mathrm{CO}+\mathrm{H}_{2} \mathrm{O} \rightarrow \mathrm{CO}_{2}+\mathrm{H}_{2}
\end{gathered}
$$

\subsection{Inter-solid Phase Heat Transfer}

In this work, the direct solid-solid conduction through contact area $\left(Q_{p s_{\text {,dir }}}\right)$ and solid-solid conduction through in-between fluid medium $\left(Q_{p s, f l u}\right)$ are incorporated into Equation 6.

2.2.1. Direct solid-solid conduction

$$
\begin{aligned}
& \mathrm{Q}_{\mathrm{ps}, \mathrm{dir}}=\mathrm{n}_{\mathrm{s}} \mathrm{n}_{\mathrm{p}}\left(\mathrm{R}_{\mathrm{s}}+\mathrm{R}_{\mathrm{p}}\right)^{2} \sqrt{8 \pi\left(\Theta_{\mathrm{s}}+\Theta_{\mathrm{p}}\right)} \times \frac{5.36(\mathrm{~m} / \mathrm{k})^{\mathrm{s} / 5}(\mathrm{R} \cdot \mathrm{V})^{\mathrm{\gamma} / 10} \cdot \mathrm{C}}{\left(\mathrm{p}_{\mathrm{s}} \mathrm{C}_{\mathrm{p}, \mathrm{s}} \lambda_{\mathrm{g}}\right)^{-1 / 2}+\left(\mathrm{p}_{\mathrm{p}} \mathrm{C}_{\mathrm{p}, \mathrm{p}} \lambda_{\mathrm{p}}\right)^{-1 / 2}}\left(\mathrm{~T}_{\mathrm{s}}-\mathrm{T}_{\mathrm{p}}\right) \\
& \mathrm{R}=\frac{\mathrm{R}_{\mathrm{g}} \mathrm{R}_{\mathrm{p}}}{\mathrm{R}_{\mathrm{g}}+\mathrm{R}_{\mathrm{sp}}} \\
& \mathrm{m}=\frac{\mathrm{m}_{\mathrm{g}} \mathrm{m}_{\mathrm{p}}}{\mathrm{m}_{\mathrm{s}}+\mathrm{m}_{\mathrm{p}}} \\
& \mathrm{E}=\frac{4 / 3}{\left(1-\gamma_{\mathrm{g}}^{2}\right) / \mathrm{G}_{\mathrm{g}}+\left(1-\gamma_{\mathrm{p}}^{2}\right) / \mathrm{G}_{\mathrm{p}}}
\end{aligned}
$$

2.2.2. Solid-solid conduction through in-between fluid medium

$$
\begin{gathered}
\mathrm{Q}_{\mathrm{ps}, \mathrm{flu}}=\mathrm{n}_{\mathrm{s}} \mathrm{n}_{\mathrm{p}}\left(\mathrm{R}_{\mathrm{s}}+\mathrm{R}_{\mathrm{p}}\right)^{2} \sqrt{8 \pi\left(\Theta_{\mathrm{s}}+\Theta_{\mathrm{p}}\right)} \times \pi \frac{1}{\mathrm{~b}} \log \left(\frac{\mathrm{a}-\mathrm{b} \eta}{\mathrm{a}-\mathrm{b} \varphi}\right)\left(\mathrm{T}_{\mathrm{s}}-\mathrm{T}_{\mathrm{p}}\right) \\
\mathrm{a}=\frac{1}{\min \left(\mathrm{R}_{\mathrm{g}}, \mathrm{R}_{\mathrm{p}}\right)}\left(\frac{0.5}{\mathrm{k}_{\mathrm{g}}}+\frac{0.5}{\mathrm{k}_{\mathrm{p}}}+\frac{1}{\mathrm{k}_{\mathrm{g}, \text { eff }}}\right) \\
\mathrm{b}=\frac{1}{\left(\mathrm{k}_{\mathrm{g}, \text { eff }} \min \left(\mathrm{R}_{\mathrm{g}}, \mathrm{R}_{\mathrm{p}}\right)\right)} \\
\mathrm{R}_{\mathrm{ij}}=0.56 \min \left(\mathrm{R}_{\mathrm{g}}, \mathrm{R}_{\mathrm{p}}\right)\left(1-\alpha_{\mathrm{g}}\right)^{-1 / 3} \\
\mathrm{r}_{\mathrm{sij}}=\left(\frac{1.25 \mathrm{mR}}{\mathrm{E}}\right)^{0.2} \mathrm{v}_{\mathrm{ps}}^{0.4}
\end{gathered}
$$




$$
\begin{aligned}
& \eta=\frac{\min \left(\mathrm{R}_{g}, \mathrm{R}_{\mathrm{p}}\right)}{\left\{\left(\min \left(\mathrm{R}_{\mathrm{g}}, \mathrm{R}_{\mathrm{p}}\right)\right)^{2}+\mathrm{R}_{\mathrm{ij}}^{2}\right\}^{1 / 2}} \\
& \varphi=\frac{\min \left(\mathrm{R}_{g}, \mathrm{R}_{\mathrm{p}}\right)}{\left\{\left(\min \left(\mathrm{R}_{\mathrm{g}}, \mathrm{R}_{\mathrm{p}}\right)\right)^{2}+\mathrm{r}_{\mathrm{gij}}^{2}\right\}^{1 / 2}}
\end{aligned}
$$

where $n, R, \Theta, \gamma$, and $T$ are the numbers of particles in the computational cell, particle radii, granular temperature, Young moduli, and temperature, respectively.

\subsection{Simulation Conditions}

Full-loop CFB geometry is applied in the simulation. There are four main components in a CFB loop: riser column, cyclone, standpipe, and return leg. Solid circulation rate is controlled by using either a mechanical valve/feeder (such as a screw feeder) or a non-mechanical valve (such as a L-valve, J-valve, or loop seal). A loop seal type is applied in the CFB geometry model to allow circulation of the solid phase.

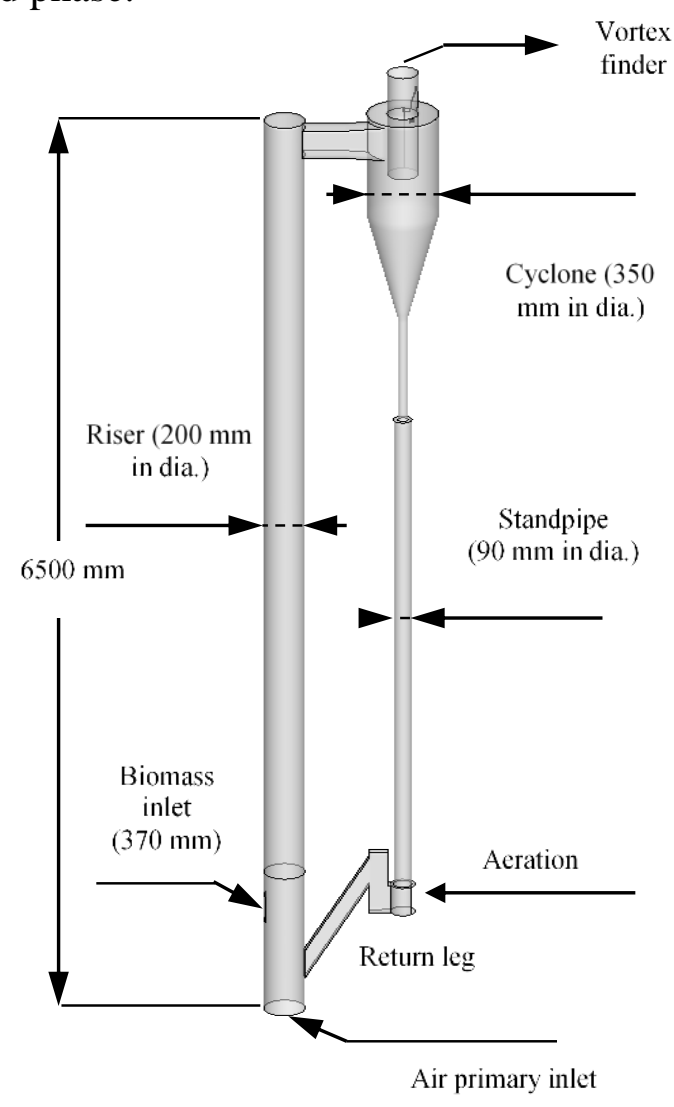

Figure 1 Geometry model representation used in the simulation

Table 1 Composition of biomass (taken from García-Ibañez et al., 2004)

\begin{tabular}{lr}
\hline Proximate analysis (wt \%) & \\
\hline Volatile matter & 74.4 \\
Fixed carbon & 17.1 \\
Ash & 8.5 \\
\hline Ultimate analysis (wt \%) & \\
\hline $\mathrm{C}$ & 52.7 \\
$\mathrm{H}$ & 7.2 \\
$\mathrm{~N}$ & 1.6 \\
$\mathrm{~S}$ & 0.07 \\
$\mathrm{Cl}$ & 0.37 \\
$\mathrm{O}$ & 38.1 \\
\hline
\end{tabular}


Table 2 Parameters used in the simulation

\begin{tabular}{lr}
\hline Biomass diameter & $1.89 \mathrm{~mm}$ \\
Sand diameter & $0.5 \mathrm{~mm}$ \\
Air flow rate & $149 \mathrm{Nm}^{3} / \mathrm{h}$ \\
Biomass feed rate & $47 \mathrm{~kg} / \mathrm{h}$ \\
Equivalence ratio & 0.73 \\
Mesh number & 263138 \\
Simulation time & $25 \mathrm{~s}$ \\
\hline
\end{tabular}

The geometry model representation is shown in Figure 1, whilst the compositions of biomass samples (on dry basis) and simulation conditions are presented in Tables 1 and 2, respectively. The sand material (with density, diameter, and volume of $2600 \mathrm{~kg} / \mathrm{m}^{3}, 0.5 \mathrm{~mm}$, and $0.019 \mathrm{~m}^{3}$, respectively) is used as an inert material. The primary air is then imposed with uniform mass flow rate at the bottom of the riser column to fluidize the bed. At the top of the finder, atmospheric pressure condition is applied. All the walls are set to no-slip and adiabatic conditions.

\section{RESULTS AND DISCUSSION}

In this section, the simulation results of the proposed model including all inter-solid phase heattransfer mechanisms (PP-all, equations 15-25), are compared to ones without inter-solid phase heat transfer (non-PP), and with direct solid-solid conduction only (PP-direct, equations 15-18), based on predictions of syngas compositions. Moreover, the spatial distributions of gas phase velocity, gas phase temperature, and $\mathrm{CO}$ mass fraction generated by the proposed model are analyzed.

Figure 2 describes the predicted syngas compositions (vol\%) for each model and the existing experimental data (Exp) of García-Ibañez et al. (2004). As shown, the predicted syngas compositions using the PP-all model, which includes all inter-solid phase heat-transfer mechanisms (direct solid-solid conduction via contact area and solid-solid conduction through in-between fluid medium), are in agreement with the experimental data, particularly for $\mathrm{CO}$, $\mathrm{CO}_{2}, \mathrm{C}_{2} \mathrm{H}_{4}$, and $\mathrm{N}_{2}$, with deviations of $28.01,11.06,38.12$ and $2.99 \%$, respectively. However, for the components $\mathrm{H}_{2}$ and $\mathrm{CH}_{4}$ the predictions are quite different from those of existing data, with deviations of 71.54 and $80.60 \%$, respectively. The poor predictions of syngas compositions for $\mathrm{CO}$ and $\mathrm{CO}_{2}$ in particular are obtained when the models of non-PP and PPdirect are applied. For example, the deviation percentages of $\mathrm{CO}$ and $\mathrm{CO}_{2}$ for the PP-direct model are 99.98 and 56.86, respectively.

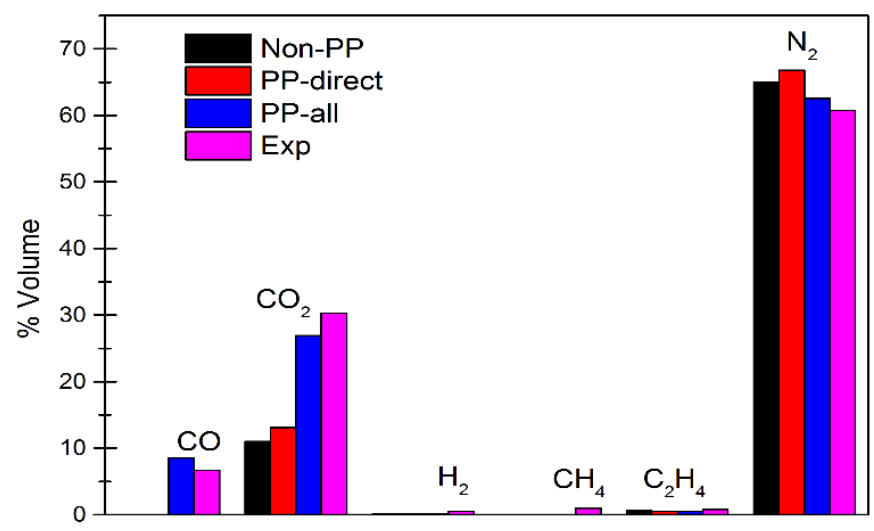

Figure 2 Effect of different treatments of inter-solid phase heat transfer mechanisms in the model on syngas composition and its comparison to the experimental data (Exp) of García-Ibañez et al. (2004) 
Moreover, Figure 2 also illustrates that the use of direct solid-solid conduction in the model (PP-direct) does not change significantly the predicted syngas composition compared to that without solid-solid heat transfer (non-PP). As pointed out by Wahyudi et al. (2016), the small amount of direct particle-particle (or solid-solid) conduction results from the small contact area of spherical particles. As a result, the solid-solid conduction through the in-between fluid medium, in addition to fluid-solid heat transfer, is a more important heat-transfer mode in determining the heat-transfer process in CFBs than direct solid-solid conduction. To sum up, Figure 2 demonstrates that the use of all the heat-transfer mechanisms of solid-solid conductions in the MFM framework can improve the model's capability to predict syngas composition at the outlet region.

Figure 3 illustrates spatial distributions of (a) solid-solid heat transfer, (b) gas phase velocity in the riser, and (c) gas axial velocity in the cyclone at macroscopically steady state. As depicted in the figures, the inter-solid phase heat transfer mainly takes place at biomass inlet, air inlet, and at the bottom region of the loop seal equipment (Figure 3a) at which the solid volume fractions are high. At other regions, solid-solid heat transfer is small. The small solid-solid heat transfer in most regions of CFBs might be due to the small volume fraction of the solid phase. Figure $3 \mathrm{~b}$ illustrates that the axial velocity of gas is high at the core region in the riser column and low at the region near the wall. The low velocity of gas at the near-wall region corresponds to the non-slip wall conditions applied in the model.

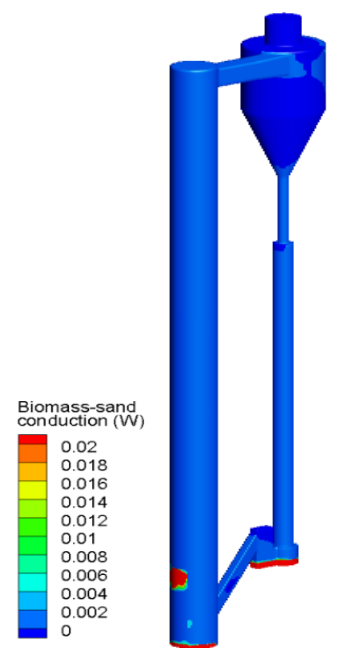

(a)

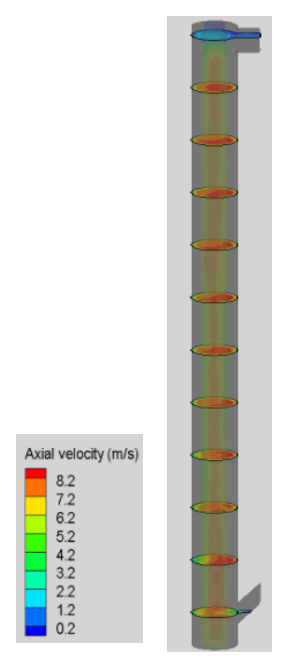

(b)

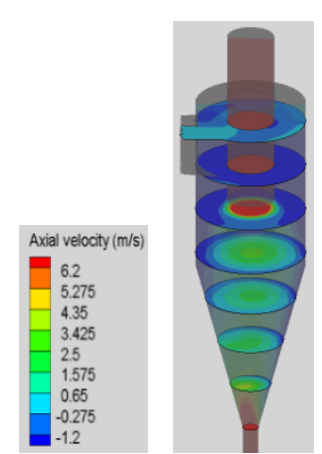

(c)

Figure 3 Spatial distributions of: (a) solid-solid heat transfer; (b) gas axial velocity in the riser; and (c) gas axial velocity in cyclone at macroscopically steady state

Moreover, gas phase velocity in the bottom region of the riser is generally lower than in the upper region. Whilst in the cyclone, the gas phase moves in a downward direction with low velocity at the region near the wall of the cylindrical part and flows upward with high velocity at the region below and within the vortex finder (Figure 3c). In contrast, at the conical region of the cyclone, gas moves upward with low velocity.

Figure 4 describes spatial distributions of (a) gas phase temperature, and (b) CO mass fraction in the gas phase at macroscopically steady state. As shown in Figure 4a, temperature of the gas phase is higher at the cylindrical part of the cyclone and is lower at the bottom region of the riser column than at other regions. 


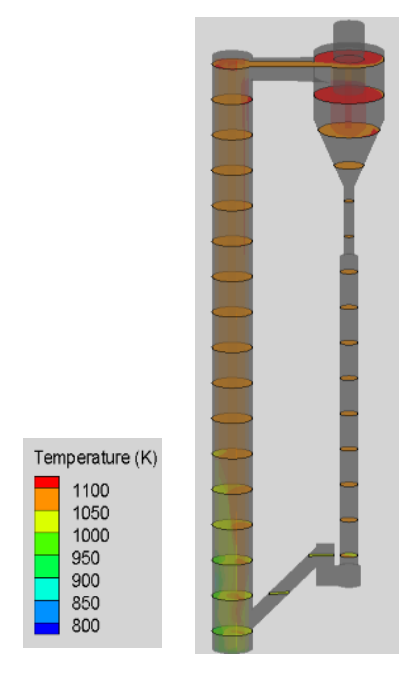

(a)

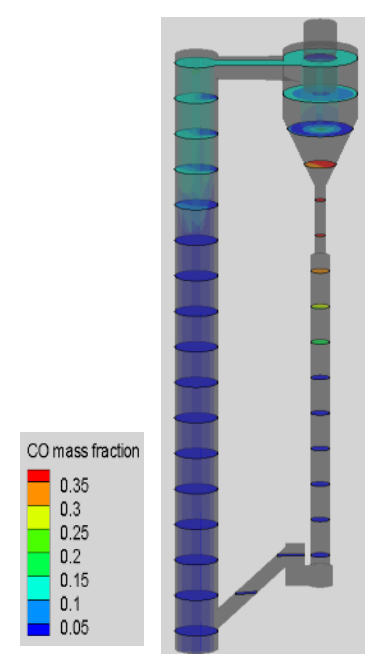

(b)

Figure 4 Spatial distributions of (a) gas phase temperature, and (b) CO mass fraction at macroscopically steady state

At the upper zone of the riser column, gas temperature is around $1080 \mathrm{~K}$ which is in agreement with experimental data $(=1083 \mathrm{~K})$ of García-Ibañez et al. (2004). The spatial temperature of the gas phase plays an important role in determining the reactions which occur in this system (see Section 2.1). For example, as shown in Figure 4b, the spatial distribution of $\mathrm{CO}$ mass fraction in the gas phase is similar to that of the gas phase temperature. $\mathrm{CO}$ mass fraction is high at the upper region of the riser column and in the cyclone and is lower at the lower region of the riser column. The high CO concentrations in the upper region of the riser column and the cyclone might be related to the high temperature of the gas phase at these regions (Figure 4a), whilst the low CO mass fraction at the bottom region of the riser column corresponds to the low temperature of the gas phase in this region.

\section{CONCLUSION}

In this work, a numerical method of MFM framework with the inclusion of inter-solid phase heat transfer (direct solid-solid conduction and solid-solid conduction through an in-between fluid medium) of biomass gasification in a 3D full-loop CFB has been developed. The effect of the inclusion of inter-solid phase heat transfer and the behaviors of hydrodynamics and heat and mass transfer are then analyzed. The following conclusions are drawn: the MFM with consideration of all inter-solid phase heat-transfer mechanisms (direct and through in-between fluid medium) has a better capability for predicting syngas composition than models without inter-solid phase heat transfer or with direct solid-solid conduction only. Furthermore, the inclusion of direct solid-solid heat transfer only in the model does not have a significant effect when compared to the model without inter-solid phase heat transfer. It is demonstrated that there is a similarity in the spatial distributions of gas phase temperature and mass fraction of components in the gas phase. For example, the high $\mathrm{CO}$ concentrations in the upper region of the riser column and the cyclone might be related to the high temperature of the gas phase at these regions.

\section{ACKNOWLEDGEMENT}

The authors are grateful to the Directorate General of Higher Education, Ministry of Research, Technology, and Higher Education for financial support of this work under Fundamental Research Scheme 2017. 


\section{REFERENCES}

Ahmad, A.A., Zawawi, N.A., Kasim, F.H., Inayat, A., Khasri, A., 2016. Assessing the Gasification Performance of Biomass: A Review on Biomass Gprocess Conditions, Optimization and Economic Evaluation. Renewable and Sustainable Energy Reviews, Volume 53, pp. 1333-1347

Atnaw, S.M., Sulaiman, S.A., Moni, M.N.Z., 2012. Experimental Study on Temperature Profile of Fixed-bed Gasification of Oil-palm Fronds. International Journal of Technology, Volume 3(1), pp. 35-44

García-Ibañez, P., Cabanillas, A., Sánchez, J.M., 2004 Gasification of Leached Orujillo (olive oil waste) in a Pilot Plant Circulating Fluidised Bed Reactor. Preliminary Results. Biomass and Bioenergy, Volume 27(2), pp. 183-194

Geng, C., Zhong, W., Shao, Y., Chen, D., Jin, B., 2015. Computational Study of Solid Circulation in Chemical-looping Combustion Reactor Model. Powder Technology, Volume 276, pp. 144-155

Gerber, S., Behrendt, F., Oevermann, M., 2010. An Eulerian Modeling Approach of Wood Gasification in a Bubbling Fluidized Bed Reactor using Char as Bed Material. Fuel, 89(10), pp. 2903-2917

Guan, Y., Chang, J., Zhang, K., Wang, B., Sun, Q., 2014. Three-dimensional CFD Simulation of Hydrodynamics in an Interconnected Fluidized Bed for Chemical Looping Combustion. Powder Technology, Volume 268, pp. 316-328

Guo, F., Dong, Y., Zhang, T., Dong, L., Guo, C., Rao, Z., 2014. Experimental Study on Herb Residue Gasification in an Air-Blown Circulating Fluidized Bed Gasifier. Industrial \& Engineering Chemistry Research, Volume 53(34), pp. 13264-13273

Hussain, A., Ahmed, I., Sait, H.H., Bassyouni, M.I., Hegab, A.M., ul Hasan, S.W., Ani, F.N., 2013. Experimental and Simulation Study of Fluidization Behavior of Palm Biomass in a Circulating Fluidized Bed Riser. Industrial \& Engineering Chemistry Research, Volume 52(49), pp. 17529-17537

Li, X.T., Grace, J.R., Lim, C.J., Watkinson, A.P., Chen, H.P., Kim, J.R., 2004. Biomass Gasification in a Circulating Fluidized Bed. Biomass and Bioenergy, Volume 26(2), pp. 171-193

Liu, H., Cattolica, R.J., Seiser, R., Liao, C.-h., 2015. Three-dimensional Full-loop Simulation of a Dual Fluidized-bed Biomass Gasifier. Applied Energy, Volume 160, pp. 489-501.

Liu, H., Elkamel, A., Lohi, A., Biglari, M., 2013. Computational Fluid Dynamics Modeling of Biomass Gasification in Circulating Fluidized-bed Reactor using the Eulerian-Eulerian Approach. Industrial \& Engineering Chemistry Research, Volume 52(51), pp. 1816218174

Singh, R.I., Brink, A., Hupa, M., 2013. CFD Modeling to Study Fluidized Bed Combustion and Gasification. Applied Thermal Engineering, Volume 52(2), pp. 585-614

Wahyudi, H., Chu, K., Yu, A., 2016. 3D Particle-scale Modeling of Gas-solids Flow and Heat Transfer in Fluidized Beds with an Immersed Tube. International Journal of Heat and Mass Transfer, Volume 97, pp. 521-537

Winaya, I.N.S., Putrawan, I.M.A., Hartati, R.S., Lokantara, I.P., Subawa, I.G.A.N., 2015. Fluidized Bed Co-gasification of Coal and Solid Waste Fuels in an Air Gasifying Agent. International Journal of Technology, Volume 6(6), pp. 931-937

Yu, L., Lu, J., Zhang, X., Zhang, S., 2007. Numerical Simulation of the Bubbling Fluidized Bed Coal Gasification by the Kinetic Theory of Granular Flow (KTGF). Fuel, Volume 86(5-6), pp.722-734 